\title{
Research on the Efficacy of College Students' Choosing Jobs from the Perspective of Family Education Investment
}

\author{
Xuguang Sun, Ailing Huang \\ Education College, Fujian Normal University, Fuzhou, China \\ Email: 752191721@qq.com, 576745282@qq.com
}

How to cite this paper: Sun, X.G. and Huang, A.L. (2019) Research on the Efficacy of College Students' Choosing Jobs from the Perspective of Family Education Investment. Open Journal of Social Sciences, 7, 36-50.

https://doi.org/10.4236/jss.2019.76003

Received: May 8, 2019

Accepted: May 31, 2019

Published: June 3, 2019

Copyright (c) 2019 by author(s) and Scientific Research Publishing Inc. This work is licensed under the Creative Commons Attribution International License (CC BY 4.0).

http://creativecommons.org/licenses/by/4.0/

\begin{abstract}
Family education investment is an important part of human capital investment, and one of the most important factors affecting children's talents. The sense of career effectiveness is the expected return of education investment, and it is also an important indicator to measure college students' career choice. However, there is little research on the relationship between family education investment and college students' job-seeking efficacy. On the basis of summarizing the previous studies, based on Schultz's human capital theory, this paper analyzes the influencing factors and studies the relationship between family education investment and college students' career satisfaction from the perspective of family education investment. The conclusions are as follows: First, there is a certain degree of correlation between family education investment and college students' job-seeking efficacy, but it is not the only decisive factor. Second, family education investment will have an impact on college students' job-seeking efficacy.
\end{abstract}

\section{Keywords}

Human Capital Investment, Expected Income, Family Education Investment, College Students' Job-Seeking Efficacy, Influencing Factors

\section{Introduction}

During the "two sessions" in 2019, the NPC deputies proposed to speed up the process of family education legislation. On the one hand, it regulates the parenting style of children's education, and avoids the phenomenon of "living without raising" and "re-invigorating moral education"; on the other hand, it is to regulate the hot market of family education services. At present, parents are increa- 
singly inclined to invest in the education of their children. According to the latest data from the National Bureau of Statistics, the cost of education for urban residents and rural residents is increasing year by year, as shown in Table 1.

Although the investment in family education is hot, there are still unreasonable investment behaviors, focusing only on material inputs and ignoring the input of time and energy. This is very unfavorable for the development of children's self-awareness. Lei Wanpeng and Xiang Rong found that the "income first" model believes that the development of the family economy is the primary goal of family development. Only by earning enough money can the children attend high school to go to college. Therefore, the educational investment in children's time and energy will be neglected [1]. In addition, with the fierce competition in the workplace of today's society, the growth environment of children will inevitably lead to different senses of professionalism. Improving college students' career effectiveness will help them succeed in the workplace.

Regarding the issue of family education investment and college students' career satisfaction, many researchers have carried out some exploration and analysis in recent years, mainly focusing on the following aspects: First, from the perspective of family education investment, Li Jie analyzed the influencing factors of rural family education investment in ethnic areas, and found that: family education investment is related to many factors such as urban-rural dual structure, family income level, social culture, parental education level and number of children [2]. Yang Xuan analyzed the main problems in the investment of family education in China, and found that the investment burden is too heavy, the investment in moral education is insufficient, and the lack of investment by family educators is the main worry [3]. Jin Xuan, Liu Min and Wang Yang collected data through scale survey and built the binary logistic model which is developed into quantitative analysis, and the factors affecting the investment in human capital in the family are discussed. The relevant conclusions that affect the human capital investment in family education are obtained [4]. In the second aspect, Huang Ruifeng, Cao Leping, and Wang Yi discussed the influencing factors of college students' career satisfaction from two aspects: personal factors and environmental factors [5]; Ni Hai passed the self-made questionnaire to investigate and study the college students' sense of career effectiveness, and found that there is a difference in the level of career effectiveness and family status [6]. However, summing up the research results of predecessors, we can find some limitations on the research of family education investment and college students' job-seeking efficacy. First, there are many studies on family education investment and college students' job-seeking efficacy. Second, the research on the influencing factors only

Table 1. Chinese family spending on education (unit: RMB).

\begin{tabular}{lccccc}
\hline & 2017 & 2016 & 2015 & 2014 & 2013 \\
\hline Urban residents' expenditure on education & 2847 & 2638 & 2383 & 2142 & 1988 \\
Rural residents' spending on education & 1171 & 1070 & 969 & 860 & 755 \\
\hline
\end{tabular}


stays at the show, and does not analyze the essence of the influencing factors. Third, with the continuous deepening of China's economic system reform, the family education investment has also undergone profound changes, and the impact of family education investment on the growth of children. No research has been done yet.

Family education investment is one of the important topics in human capital investment. Especially the relationship between human capital investment and expected income is an important research task in the education economy. Therefore, the research on scientific family education investment and college students' job-seeking efficacy is an important beginning to study human capital investment and income. This study attempts to study the relationship between family education investment and college students' job-seeking efficacy from the perspective of family education investment, and draws conclusions to propose countermeasures to improve the status of family education investment.

\section{Concept Analysis}

With regard to the concept of family education investment and the concept of college students' career choice, the academic circles have made various interpretations. The author believes that:

\subsection{The Concept of Family Education Investment}

Education investment is a kind of human capital investment, which is of great significance in the whole social and economic development. Part of the investment in education comes from government spending, which is mainly responsible for education funding during the compulsory education stage. Another part of the investment comes from investment in family education. The investment in family education reflects the investment of each family in education. Zhao Ning, Zhang Yan and Wang Hua suggested that "the general investment in family education is part of the total investment of the family. It includes not only the material input, the opportunity cost, but also the investment of time and energy. The narrow family education investment It is the cost of all kinds of education that the family spends on the family before the economy is independent" [7]. The concept of family education investment involved in this study includes both broad and narrow concepts.

\subsection{The Concept of College Students' Career Satisfaction}

The concept of job-seeking efficacy stems from Bandura's theory of self-efficacy and Kletz's theory of professional maturity. Bandura (1977) revealed that self-efficacy refers to expectations and estimates of people's ability to accomplish a particular goal. The low self-efficacy of an individual in a certain behavior can lead to poor performance of the individual in this aspect, and high self-efficacy will improve the individual's performance in a certain behavior. In past research, Zheng Ying quoted the theory of professional maturity proposed by Kletz. He 
believes that there are five abilities related to career choices. Five abilities and mature attitudes will promote individuals to make a good career decision. The five competencies are the ability to accurately self-evaluate, collect professional information, target screening, develop future plans, and solve problems [8]. And Zheng Ying also suggested that "in 1983, American psychologists Taylor and Bates combined self-efficacy and professional maturity theory to propose a sense of "career effectiveness", defined as: the individual's confidence in the ability to accomplish related goals in the career selection process" [9]. The "student's job-seeking efficacy" in this study refers to the confidence of college students in their ability to find a suitable job and be competent in a job when they face career choices in the future.

\section{The Factors Affecting Family Education Investment and College Students' Career Satisfaction}

\subsection{Factors Affecting Family Education Investment}

\subsubsection{Different Family Basic Conditions Will Affect the Family's Educational Investment}

From the perspective of residential area, education as a kind of human capital investment is inevitably affected by regional ideas. Conservative ideas have greatly influenced the intensity and enthusiasm of family education investment. Families living in the eastern region will be willing to invest more in their education for their children because they accept more open and diverse ideas. Chen Hui's research found that parents' educational awareness and educational philosophy are closely related to their parents' education and occupation. Specifically, parents' educational awareness and educational concepts influence the quality of family education investment and resource utilization efficiency. The reason for the above difference is that the rational orientation dimension of the eastern region is higher than that of the western region, which is due to the comprehensive population quality of the eastern and western regions [10]. Pan Yunhua and Xue Rui revealed that from the perspective of the urban-rural dual structure, the income of families living in cities is higher than that of rural families, and their children receive higher education investment than rural families. The main reason behind this is the huge difference in urban and rural income due to the urban-rural dual structure [11]. From a conceptual point of view, the concept is influenced by the economic level. Compared with cities, rural areas have more supporters of "reading uselessness". Li Jie found that from the perspective of the number of children and the gender of the children, the family income is certain, and the more people are educated, the less the education cost of investing in each child is reduced [12]. In a multi-child family, if it is a boy, investment in education will be further reduced. If there are both boys and girls, the family is more inclined to invest in boys when the income level of the family is low, especially in rural areas. In the one-child family, the family income is excluded, and the investment in family education for boys and girls is basically the same. 


\subsubsection{Family Income Is an Important Factor Restricting Family Education Investment}

Household income is an important factor that restricts investment in family education. Research showed that family income is directly proportional to family education investment. Under other conditions, the higher the income level, the greater the possibility of investment education. For low-income families, household income is more about spending on daily life, especially food consumption, and the proportion of investment in education will decrease. According to the latest data from the National Bureau of Statistics, although the education expenditure of rural residents is increasing year by year, the proportion of educational investment is seriously insufficient compared with the cost of daily life. As shown in Table 2, food expenditure is the largest proportion of rural household consumption expenditure, and other daily expenses account for nearly $90 \%$ of total consumption expenditure. Therefore, the level of household income is an important manifestation of family education investment ability.

\subsubsection{Parental Education and Social Status Will Affect Family Education Investment}

On the one hand, the higher the level of education of parents, the higher the awareness of the importance of investment in education, and the higher the educational expectations of their children. Therefore, parents will be more willing to invest in high-education human capital for their children. Not only will they have higher physical inputs, but they will also pay more attention to investment in time, such as spending time with their children and paying attention to parent-child education. In present study, Li Jie found that for families with lower education level, parents have "arbitrary" education on their children, that is, to what extent, is less able to talk about investment in time. As a result, parents have a certain degree of "arbitrariness" in their investment in education [13]. On the other hand, the social status of parents will have an impact on the importance of their children's education investment. Parents are in different social

Table 2. Daily expenses and educational investment of rural residents (unit: RMB).

\begin{tabular}{|c|c|c|c|c|c|c|}
\hline & & 2017 & 2016 & 2015 & 2014 & 2013 \\
\hline \multicolumn{2}{|c|}{ Total expenditure on consumption } & 10955 & 10130 & 9223 & 8383 & 7485 \\
\hline & $\begin{array}{l}\text { Food, tobacco and alcohol consumption } \\
\text { expenditure }\end{array}$ & 3415 & 3266 & 3048 & 2814 & 2554 \\
\hline & Clothing consumption expenditure & 612 & 575 & 550 & 510 & 454 \\
\hline & Residential consumption expenditure & 2354 & 2147 & 1926 & 1763 & 1580 \\
\hline \multirow[t]{4}{*}{$\begin{array}{l}\text { Other daily } \\
\text { expenses }\end{array}$} & Household goods consumption expenditure & 634 & 596 & 546 & 506 & 455 \\
\hline & $\begin{array}{l}\text { Transportation and communication } \\
\text { consumption expenditure }\end{array}$ & 1509 & 1360 & 1163 & 1013 & 875 \\
\hline & Healthcare consumption expenditure & 1059 & 929 & 846 & 754 & 668 \\
\hline & Other supplies consumption expenditure & 201 & 186 & 174 & 163 & 144 \\
\hline \multicolumn{2}{|c|}{ Educational consumption expenditure } & 1171 & 1070 & 969 & 860 & 755 \\
\hline
\end{tabular}


classes, have different social resources, and have different ideas and ideas. For the middle-class families in our country, the education environment and the influence of the surrounding people do not want children to lose at the starting line. Under the premise of being affordable, they will be more willing to invest in their education, such as: purchasing school districts. Read private schools, etc. For the wealthy high-class class, if parents are highly educated or have high educational expectations, they will invest more in their children's education; if parents do not have high educational expectations, there will be "arbitrariness" in education investment. For the low-income class, due to the lack of material conditions, parents will have greater "arbitrariness" in their children's education investment, and even interrupt their education investment.

\subsubsection{Children's Own Learning Status Will Affect the Enthusiasm of Parents' Investment in Education}

If the children's own learning status is good, parents will be more willing to invest in their children's education. Parents will do their best to support their children's learning, and the proportion of investment in education will be greater. Investment will not only favor material investment, but also willing to spend more time with them. Children learn; if the children's own learning status is poor, parents will feel that the child is hopeless to go to school and reduce the enthusiasm for their children's education investment. According to the quantitative analysis of Li Min, Zhao Liange and Tan Hongbo, it is found that the influence of children's own learning status on their years of education is the most important [14]. Although parents will make up for the children with poor academic performance and increase the investment in family education, the children's own learning ability is poor, and parents will lose the motivation to invest in education. Li Min, Zhao Liange and Tan Hongbo have confirmed this view. It can be seen that the children's academic performance is directly proportional to the family education investment.

\subsection{Influencing Factors of College Students' Career Satisfaction}

\subsubsection{Family Situation Is an Important Factor Affecting College Students' Career Satisfaction}

On the one hand, parents' education level reflects the values of parents. Well-educated parents are good at encouraging children to explore their careers and provide support and help. On the other hand, the level of household income means whether it has more advantageous resources in society and whether it can provide a more relaxed environment and more sufficient conditions for children to achieve their ideals. A good student's family status means that he has more chances of success, and he has a wealth of successful experiences in his past experience, which naturally increases his level of self-efficacy. The family is in a bad state, whether it is a poor economic situation or a bad social background, which means that students cannot get family support when they choose a career. They cannot get more successful experiences in past experiences, which leads to 
their low self-evaluation. Lack of self-confidence.

\subsubsection{The One-Child's Job-Seeking Efficacy Will Be Higher than That of Non-Only Children}

The study concluded that there is no difference between the overall adaptation of the only child and the non-only child and the social ability. The only difference is that the achievement motivation of the only child is higher than that of the non-only child. The main reason for this may be that the only child has a closer relationship with their parents, and parents are more demanding and expecting them. Therefore, when choosing a career, the self-efficacy of the only child will be higher than that of the non-only child.

\subsubsection{Gender Differences Affect the Career Choices of Children}

The influence of gender on college students' job-seeking efficacy is mainly reflected in the differences in male and female abilities. According to psychological research, women are better than men in terms of perception, attention, and image thinking. Women are not as good as men in terms of spatial perception, logical memory, and abstract thinking. Differences in the types of abilities can affect a child's choice of career, so there is a scruple about career choices.

\subsubsection{Personality Traits Will Affect College Students' Job-Seeking Efficacy} Some characteristics of personality are related to the sense of career effectiveness. Liu Yongxian showed that "there are significant positive correlations between the four dimensions of extroversion, openness, amenity and emotional stability in the Big Five personality. And the three dimensions of extroversion, emotional stability and openness in the Big Five personality dimension can predict the effectiveness of career choice" [12].

\subsubsection{Achievements Affect the Self-Confidence of College Students}

Achievement motivation is closely related to college students' academic performance. Academic achievement is an important manifestation of academic achievement and an important source of self-confidence for college students. If the academic performance is good, the students will have a high sense of self-efficacy. Similarly, self-efficacy will migrate to the career selection process and will be full of confidence when choosing a career. On the contrary, when you choose a career, you will be afraid.

\subsubsection{Work Experience Will Affect College Students' Expectations of Their Career Choices}

Past experience information will affect college students' expectations of their career choices. Successful experience information will enhance college students' self-confidence and enable students to build a stable and stable self-efficacy. And have had work experience, when choosing a career, there will be more clear goals, know what kind of work you want to find, think and make decisions will be more appropriate to your actual situation, and make a reasonable career choice. 


\section{The Relationship between Family Education Investment and College Students' Career Satisfaction}

By analyzing the factors affecting family education investment and college students' job-seeking efficacy, it can be seen that the factors affecting family education investment and college students' career satisfaction are not the same, indicating that there is a certain relationship between them.

\subsection{The Theoretical Basis of the Relationship between Family Education Investment and College Students' Career Satisfaction}

Qu Hengchang and Zeng Xiaodong noted that Schultz elaborated on human capital theory at the annual meeting of American economics in 1960. Schultz et al. proposed that human capital is a kind of capital that can be embodied in people and can provide people with future income. Education investment is human capital. Core. Education is a productive investment that plays a pivotal role in economic growth. Because the key to economic growth is to improve the quality of labor, thereby greatly improving labor productivity; and the main way to improve labor productivity and labor quality is education [13]. Zhao Yuan found that in terms of income, education investment is an expected income, including both expected profit and opportunity cost. The expected profit is related to the enthusiasm of the investment entity and the amount of investment is related to the expected investment profit [14]. This study is based on Schultz's human capital theory to study the relationship between human capital investment and expected returns. Specifically, this study uses family education investment as an indicator of human capital investment, and measures the profit (expected income) obtained by college students in their future career choices based on their career choices, so as to study the relationship between family education investment and college students' job-seeking efficacy.

\subsection{Analysis and Discussion on the Relationship between Family Education Investment and College Students' Career Satisfaction}

This study analyzes the influencing factors from the aspects of family education investment and college students' career satisfaction, finds the common factors and different factors of the two, and explains the relationship between the two through factor analysis. From the results, there is a certain degree of correlation between family education investment and college students' job-seeking efficacy. At the same time, family education investment will affect college students' career satisfaction.

\subsubsection{There Is a Certain Degree of Correlation between Family} Education Investment and College Students' Job-Seeking Efficacy

1) The relationship between residential area, urban-rural dual structure and number of children in family education investment is related to college students' job-seeking efficacy

The basic family situation in family education investment includes residential 
area, urban-rural dual structure, number of children and gender of children. These factors are related to family situation, number of children and gender factors in college students' job-seeking efficacy. The residential structure and the urban-rural dual structure will affect the parents' education and family income levels, which will have an impact on college students' career choices. Specifically, the more developed the regional economy, the more open-minded parents, the higher the family income level, the more parents will support and encourage children to explore, and the more opportunities for success, the higher the college students' sense of job-seeking efficacy. There is also a correlation between the number of children in family education investment and the number of children in job-seeking efficacy. The only child family is more than the only child, and the proportion of investment in education is greater. The children's academic performance is usually better, and the parents will have more expectation. Therefore, the job-seeking efficacy is higher. The gender of children in family education investment is not related to the gender of children in college students' job-seeking efficacy. The reason is that the gender difference of children in family education investment is mainly reflected in the amount of investment in education. The gender difference in college students' job-seeking efficacy is reflected in the difference in ability development, so the gender of the child is not related.

2) Parent education level and parental social status in family education investment are related to college students' job-seeking efficacy

The higher the education level of parents, the more open-minded their minds, the higher their awareness of investment in education, and the more they are willing to invest in their children in education. On the other hand, the higher the social status of parents, the greater the social resources, the greater the chances of their children succeeding. Both of these aspects are externally superior, and a good environmental atmosphere will enhance children's self-confidence. Therefore, there is a positive correlation between parental status and college students' career satisfaction.

3) Children's academic achievement in family education investment is related to college students' job-seeking efficacy

The child's academic achievement represents a certain degree of motivation for the child's achievement and is an important source of self-confidence. If the children's academic performance is good, the parents' investment enthusiasm in education will be higher, which will lead to the children's learning enthusiasm and learning motivation, and the children's self-efficacy will be higher. Similarly, self-efficacy will also migrate to career choices, and will be full of confidence when choosing a career. Therefore, there is a positive correlation between children's academic achievement and college students' job-seeking efficacy.

4) There is a certain degree of correlation between family education investment and college students' career satisfaction

Among the many factors that affect the sense of career effectiveness, there are work experience, personality and so on. Family education investment is not di- 
rectly related to these factors. Because work experience will affect college students' job-seeking efficacy, but it does not necessarily affect the family's enthusiasm for investment in education; and personality will significantly affect college students' job-seeking efficacy. For family education investment, parents' education investment will not be affected by sub-woman traits. Because personality can only explain the stable and unified psychological quality of a person, and does not represent the individual's achievements, it does not affect the investment in family education. In addition, parents with high social status and educational expectations in family education investment may be inclined to invest in high education. In the sense of college students' career choice, only the high social status of parents will improve the efficiency of college students' career choice, and will not consider other factors. Impact. Therefore, there is a certain degree of correlation between family education investment and college students' job-seeking efficacy, but it is not completely relevant.

\subsubsection{Family Education Investment Will Have an Impact on College Students' Job-Seeking Efficacy}

Based on the research on family education investment and college students' career satisfaction, we find that family education investment will affect college students' job-seeking efficacy. Specifically, the residential area and urban-rural dual structure will affect the level of education and family income of parents. The more open-minded parents think, the higher the family income level, parents will pay attention to the education of their children and the quality of their children, which will enhance their children's self-confidence. In addition, under the premise of a certain family income, the only child will enjoy more education investment than the non-only child, and the parents' educational expectation will be relatively high. According to the "Pygmalion" effect ${ }^{1}$, the children's academic performance will be relatively Better, and then there will be strong motivation for achievement, and self-confidence will increase. The above-mentioned influencing factors are derived from family education investment. Therefore, we can further conclude that family education investment will have a certain degree of influence on college students' job-seeking efficacy.

In summary, the residential area, urban-rural dual structure, number of "Pygmalion" effect, also known as "Rosental effect" or "expectation effect", was proved by the famous American psychologists Rosenthal and Jagbson in the teaching of primary schools, saying that people will not Consciously accept the influence and suggestion of people who like, admire, trust, and admire, thereby showing the behavior expected by the other party. Psychological resilience and psychological capital, psychological resilience refers to the individual's psychological and behavioral responses to environmental changes. It is not fixed, it changes with the change of external situation, and gradually achieves balance and adaptation. Psychological capital refers to the positive psychological state that the individual manifests in the development process, including positive and optimistic attitude, self-confidence, willpower, etc., which is an important psychological potential in individual growth. "Microsystems" is proposed by Brownfinbrenner in his ecosystem theory, focusing on the impact of the environment on human psychology and behavior. He proposed four environmental systems, from small to large: microsystems, medium and outer systems, and macrosystems. From microsystems to macrosystems, the impact on children ranges from direct to indirect. Microsystems are environments that have the most direct impact on people, mainly households, schools, peers, and networks. 
children and household income level will have an impact on family education investment, and it is also an important predictor of college students' job-seeking efficacy. In addition, family education investment and college students' job-seeking efficacy will also be affected by parents' education and their children's academic performance. It is concluded that there is a certain degree of correlation between family education investment and college students' job-seeking efficacy, but it is not completely related; family education investment will have a certain impact on college students' job-seeking efficacy.

\section{The Practical Path of Improving the Efficiency of College Students' Career Choice from the Perspective of Family Education Investment}

The conclusions of this study are: under the premise of good family income, the more developed the regional economy and the one-child family living in the city, the higher the education level of the parents, the better the children's academic performance, the more parents tend to invest in education; The more effective the children are in their career choices. However, family education investment is not completely related to college students' job-seeking efficacy. At the same time, family education investment is only partially affected by college students' job-seeking efficacy, not the only factor. Therefore, based on the above research perspectives, it is instructive for the improvement of the status quo of family education investment and the improvement of college students' career selection efficiency.

\subsection{Family Perspective: Changing the Concept of Family Education Investment, Attaching Importance to the Cultivation of Internal Qualities Such as Personality}

As this study shows, for wealthy families, if parents do not have educational expectations, they will not be inclined to invest in education. Therefore, it is important to change the concept of family education. On the one hand, Zhao Yuan believed that families must rationally plan their investment in family education, and they must pay attention to both long-term interests and short-term returns [14]. Fully consider the developmental characteristics of children and let them participate in the decision-making of family education investment. On the other hand, transforming the concept of a single education investment. Family education investment is not only a material investment, but also includes parents' investment in time, such as: talking with children, cultivating children's interests, etc., including the quality of parents' education and the creation of a good family education environment. Considering moral and cultural investment, a good educational concept is formed, and education is emphasized.

Studies have shown that the influence of family on personality development is the most important and most significant in a person's life. Therefore, in the family, we must pay attention to the shaping of the family culture atmosphere, especially the "micro system" that children directly contact. Give children a relaxed 
and fulfilling environment, encourage children to participate in family decision-making and free exploration, give full play to children's autonomy, and form a democratic family education. In school, not only must we impart knowledge and skills in an orderly manner, but also purposefully and consciously cultivate students' self-confidence, and do not succeed in academic achievement.

\subsection{Personal Point of View: Increase Personal Social Experience, Improve the Efficiency of College Students' Career Choice from Internal Mechanism}

On the one hand, the individual's social experience, especially work experience, has a significant impact on career satisfaction. Students who have had a work experience have a higher level of career satisfaction than those who do not have a work experience. Therefore, colleges and universities should encourage college students to go out of school, provide opportunities for students to work part-time, internships, increase their own practical experience, guide students to transform their own learning into what they use, so that students can understand their professional prospects and understand their interests and abilities. To set the direction for career choice and employment in the future.

On the other hand, guiding the family to change the concept of family education investment, broadening the investment channels of education funds, and increasing social experience are only to improve the efficiency of college students' career choice from external factors. The key is to improve the efficiency of college students' career choice from the internal mechanism of college students. It is not enough to rely solely on external factors. What is more important is to improve the efficiency of college students' career choice through internal mechanisms. Therefore, students should have a deep understanding of the majors they have studied and master solid professional knowledge. It is necessary to have an objective and correct self-awareness for yourself so that you can make accurate judgments when choosing a career. In addition, through a series of practical activities to enhance their adaptability, they have better psychological flexibility and stronger psychological capital. At the same time, students themselves must maintain a positive emotional state, develop a suitable goal plan, increase the individual's successful experience, and continuously enhance self-confidence and cognition.

\subsection{Government Perspective: Speeding up Family Education Legislation and Broadening Investment Channels for Education Funding}

On the one hand, because the child has an attachment before the age of 12, this is also the key period for the family to educate the child. The child needs the parents to accompany him most during this period. Therefore, it is necessary to speed up the implementation of family education legislation, put an end to the phenomenon of "living without raising" and "cultivating and not breeding", and resolutely curb "widowed child-rearing". At the same time, we must learn more 
about the situation of children, establish parent committees, and care for children. Growing up, the school knows about family education activities.

On the other hand, the implementation of the sharing mechanism of education expenses in China has played a huge role in promoting the development of education. However, from the current point of view, the sharing of education costs in China is mainly concentrated in the stage of compulsory education, and the cost of education for high schools and universities is relatively small. For families with many children or poor families, the pressure on family education investment is enormous, and even the children drop out of school. Therefore, the government should introduce relevant policies to improve the green channels such as school awards, bursary systems, and student loans. At the same time, through the means of talent transfer, social organizations or enterprises are encouraged to donate education funds to form a multi-channel mechanism for raising education funds.

\subsection{Social Perspective: Improve Self-Confidence with Psychological Counseling}

The survey shows that many college students are full of fear and confusion about the future, which leads to the phenomenon of being at a loss when faced with employment. Therefore, schools can open psychological counseling centers, use career planning, counseling and lectures to strengthen students' professional values education, enhance students' self-confidence, help students establish a correct outlook on employment and career choices, and guide students to understand society and Occupation, improve students' ability to adapt to career choices and adjust their career choices. At the same time, the school and relevant government departments can provide students with a wealth of employment information, such as special employment counseling sessions, job fairs, etc., to increase the chances of students finding their favorite jobs.

In summary, a good family environment (such as material input and time investment, family atmosphere and parental education level), the government's comprehensive support policies and rich social experience are very beneficial to college students' career efficiency. However, only the superior external environment is not enough to enhance the college students' sense of job-seeking efficacy. It is necessary to fully explore the internal motivation of college students and psychologically stimulate the self-confidence and career-seeking efficacy of college students.

\section{Conclusion}

In summary, from the perspective of family education investment, the relationship between family education investment and college students' job-seeking efficacy is studied. The conclusions are as follows: First, there is a certain degree of correlation between family education investment and college students' career satisfaction, but not the only determinant; the second is that family education in- 
vestment will have an impact on college students' job-seeking efficacy.

\section{Weakness}

This paper mainly adopts the speculative method, expounds the relationship between family education investment and college students' job-seeking efficacy. It does not quantify the family education investment and college students' job-seeking efficacy. It has certain subjectivity. Therefore, in the next study, an empirical study will be conducted to test the relationship between family education investment and college students' job-seeking efficacy.

\section{Conflicts of Interest}

The authors declare no conflicts of interest regarding the publication of this paper.

\section{References}

[1] Lei, W.P. and Xiang, R. (2018) Learning Adaptability of Left-Behind Children and Rationality of Decision Making in Family Education. Journal of Central China Normal University, No. 6, 174-182.

[2] Li, J. (2016) Analysis on Factors Influencing the Education Investment Capacity of Rural Families in Minority Nationality Regions. The Science Education Article Collects, No. 3, 123-124.

[3] Yang, X. (2018) Analysis and Countermeasure Research on Family Education Investment Behavior in China. Marketing Management Review, No. 7, 209.

[4] Jin, X., Liu, M. and Wang, Y. (2018) An Empirical Study on the Influencing Factors of Human Capital Investment in Family Education Based on Logistic Model: A Case Study of Shuyang County Jiangsu Province. Modern Economic Information, No. 13,490 .

[5] Huang, R.F., Cao, L.P. and Wang, Y. (2018) Review of Influencing Factors in College Students' Career Decision Making Self-Efficacy. China University Students Career Guide, No. 9, 49-53.

[6] Ni, H. (2018) Investigation and Research on the Status Quo of College Students. Journal of Campus Life \& Mental Health, No. 2, 106-109.

[7] Zhao, N., Zhang, Y. and Wang, H. (2014) Analysis of Family Education Investment Behavior: Based on the Survey of Fuxin City, Liaoning Province. Higher Agricultural Education, No. 4, 116.

[8] Zheng, Y. (2010) A Summary of the Research on College Students. Work \& Study Abroad, No. 16, 46-47.

[9] Chen, H. (2014) Research on the Influence of Family Education Investment on Education Reform and Development: Based on Data Survey of 2000 Households in 4 Provinces. Master's Thesis.

[10] Pan, Y.H. and Xue, R. (2018) Multi-Layer Analysis of Family Education Investment: Based on the Application of CFPS2014 Data. Journal of Shanghai Educational Research, No. 5, 35.

[11] Li, M., Zhao, L.G. and Tan, H.B. (2006) Analysis of Factors Affecting Family Education Investment in Rural Areas: Taking Chengde City of Hebei Province as an Example. Journal of Agrotechnical Economics, No. 5, 73-78. 
[12] Liu, Y.X. (2013) Influencing Factors and Intervention of College Students' Career Efficacy. Adult Education, No. 12, 101-102.

[13] Qu, H.C. and Zeng, X.D. (2000) The Theoretical Basis of Western Educational Economics: Human Capital Theory. In: Wang, M.S., Series Ed., Western Educational Economics Research, Beijing Normal University Press, Beijing, 25-39.

[14] Zhao, Y. (2015) Investigation on the Status Quo, Problems and Countermeasures of Family Education Investment. Journal of Yan' an Vocational \& Technical Institute, No. 3, 8-9. 